\title{
STRUKTUR FORMA GEGURITAN SUDDHAMALA
}

Oleh :

Kadek Dedy Herawan' ${ }^{1}$ I Ketut Sudarsana ${ }^{2}$

\begin{abstract}
Abstrak
Struktur forma Geguritan Suddhamala terdiri dari : kode bahasa dan sastra yaitu geguritan ini ini yakni menggunakan 182 bait (pada) pupuh dan terdiri atas 22 bait Pupuh Sinom, 46 bait Pupuh Ginada, 51 bait Pupuh Durma, 18 bait Pupuh Semarandana, 30 bait Pupuh Pangkur dan 15 bait Pupuh Dangdang Gula.Ragam bahasa yang digunakan dalam geguritan Suddhamala ini menggunakan Bahasa Bali Alus, Bahasa Bali Madya, dan Bahasa Bali Kasar. Gaya bahasa yang digunakan dalam geguritan Suddhamala menggunakan majas litotes, perumpamaan, antitesis, pleonasme, hiperbola dan antonomasia. Geguritan Suddhamala memiliki tema mayor yaitu ajaran penyucian, kemudian tema minornya adalah pendidikan karakter. Pesan moral atau amanat yang terdapat dalam Geguritan Suddhamala adalah sebagai manusia hendaknya selalu berbhakti kepada Tuhan Yang Maha Esa, berbuat baik, hormat kepada semua orang, bersyukur serta menjalankan ajaran dharma untuk bisa menyucikan/menyadarkan diri sendiri atau orang lain.
\end{abstract}

Kata Kunci : Struktur, Geguritan Suddhamala.

\section{Abstract}

The structure forma Geguritan Suddhamala consists of: code language and literature is geguritan this is the use of 182 pupuh stanzas and consists of 22 Sinom stanzas, 46 Ginada stanzas, 51 stanzas Durma, 18 Semarandana stanzas, 30 Pangkur stanzas and 15 Dangdang Gula stanzas. Language level used in this Suddhamala geguritan uses Bali Alus language, Bali Madya language, and Bali Kasar language. The style of language used in geguritan Suddhamala using a figure of speech litotes, parable, antithesis, redundancy, hyperbole and antonomasia. Geguritan Suddhamala have a major theme of the doctrine of sanctification, then the minor theme is character education. The moral or mandate contained in Geguritan Suddhamala is as a man should always berbhakti to God Almighty, do good, respectful to everyone, as well as the teachings of dharma grateful to be able to purify / sensitize oneself or others.

Keywords: Structure, Geguritan Suddhamala

\section{PENDAHULUAN}

Geguritan merupakan salah satu struktur kesusastraan Bali yang berstruktur tembang. Geguritan secara etimologi berasal dari kata 'gurit' yang berarti menulis atau mengarang. Kata 'gurit' yang merupakan struktur kata kerja kemudian mengalami pengulangan sebagian pada suku kata awal (dwipurwa) dan mendapatkan akhiran -an, sehingga menjadi geguritan, yang merupakan kata benda yang dapat diartikan sebagai suatu tulisan atau karangan yang mengandung sebuah lakon cerita dalam struktur tembang.

Gautama (2007: 51) menyatakan bahwa geguritan merupakan suatu nyanyian yang menceritakan suatu lakon dalam pepalihan (bagianbagian) yang terdiri dari pupuh-pupuh. Kumpulan pupuh yang membangun sebuah geguritan dapat berupa satu jenis pupuh atau beberapa jenis pupuh yang berbeda. Karena terdiri dari beberapa pupuh yang memiliki aturan yang jelas dalam penulisannya, geguritan digolongkan menjadi Kesusastraan Bali Purwa atau kesusastraan Bali yang bersifat klasik atau tradisional.

Berdasarkan penjabaran tersebut, simpulannya bahwa geguritan merupakan suatu kumpulan dari beberapa pupuh baik yang sejenis maupun yang berbeda jenis, yang mengandung sebuah lakon yang diceritakan secara naratif. Masing-masing jenis pupuh memiliki aturan-aturan yang membedakan satu pupuh dengan yang lainnya. Aturan ini dikenal dengan istilah pada lingsa. Tinggen (1982) menyatakan bahwa pada lingsa berasal dari dua kata yaitu pada dan lingsa. Kata 'pada' yang secara harfiah berarti bait, dalam hal ini diartikan sebagai jumlah baris dalam satu bait, dan jumlah suku kata dalam satu baris. Sedangkan kata 'lingsa' berarti bunyi akhir dalam setiap baris. Jadi, pada lingsa adalah aturan dalam sebuah bangun pupuh, yang mengikat jumlah suku kata dalam tiap baris, jumlah baris dalam satu bait, dan bunyi/ vokal terakhir pada tiap baris.

Pada lingsa yang ada ini dipenuhi dan diikuti oleh setiap pengarang agar karya satra yang diciptakan dapat diterima secara umum oleh masyarakat luas sebagai penikmat sastra. Selain memiliki aturan pada lingsa yang khas untuk setiap jenis pupuh, masing-masing pupuh tersebut juga memiliki karakteristik yang berbeda.

Suddhamala secara etimologi terstruktur dari dua unsur, yaitu 'Suddha yang artinya pembersihan dan

\footnotetext{
${ }^{1}$ Kadek Dedy Herawan, Guru di SMK PGRI Denpasar

${ }^{2}$ I Ketut Sudarsana, Dosen di Institut Hindu Dharma Negeri Denpasar
} 
Mala yang artinya kotoran" yang merupakan nama tokoh dalam geguritan, yang artinya pembersih kotoran atau penyucian. Sudhamala adalah nama seorang tokoh yang diberikan oleh Dewi Dhurga kepada salah satu putra Pandu yang bernama Sahadewa pada kisah Mahabharata. Dari pemaparan tersebut, dapat disimpulkan bahwa Sudhamala berarti kisah penyucian kembali Dewi Durga yang mendapat kutukan dari Siwa yang kemudian disucikan oleh Sahadewa yang memiliki kepribadian yang thulus dan jujur sehingga Dewi Durga dapat suci kembali.

Geguritan Suddhamala yang dikaji adalah karya dari I Nyoman Tengah dalam bentuk lontar yang berjumlah 15 lembar daun lontar yang berisi 30 halaman yang disadur oleh Bapak Djendra Pura, ED dimana cerita naratif dalam bentuk nyanyian yang mengangkat kisah dari kisah penyucian Dewi Durgha oleh Sahadewa yang kemudian mendapat gelar sudhamala. Kesimpulanya adalah tulisan ini terfokus pada teks hasil saduran yang dibuat oleh bapak Djendra Pura,ED.

Geguritan Suddhamala merupakan sebuah karya sastra Bali yang berbentuk Puisi Bali Purwa. Geguritan Suddhamala ini dikarang oleh I Nyoman Tengah dari desa Pekandelan Kaler, Klungkung. Teks aslinya merupakan sebuah lontar yang tersimpan di Pusdok Dinas Kebudayaan dan Pariwisata Provinsi Bali dengan tebal halaman 30 halaman dan ukuran lontarnya adalah $25 \mathrm{Cm}$, keadaan lontar geguritan ini masih bagus dan bisa terbaca dengan jelas. Geguritan yang diteliti merupakan naskah latin yang disadur kedalam sebuah buku geguritan oleh bapak Djendrapura, Ed. Judul karya sastra ini mempunyai makna sebuah kesederhanaan dan pengendalian pikiran merupakan sesuatu hal yang sangat ampuh untuk melebur segala kotoran didalam diri manusia. Geguritan Suddhamala berisikan nilai ajaran Tattwa, Susila dan konsep pendidikan karakter yang dapat dipakai pedoman untuk membentuk suatu karakter manusia khususnya remaja untuk mendapatkan pendidikan anak yang suputra dan dapat mencapai kebahagiaan diri.

Penceritaan Geguritan Suddhamala merupakan kisah dikutuknya Dewi Uma oleh Dewa Siwa untuk menjadi tinggal dilingkungan kuburan dan akan memiliki wajah yang sangat menyeramkan sampai ada yang mampu melepaskan kutukannya, dimana sudah disampaikan yang mampu melepaskan kutukannya hanyalah manusia yang memiliki hati yang bersih tulus ikhlas. Kutukan kepada Dewi Uma untuk menjelma menjadi Durgha dikarenakan Dewi Uma tidak jujur ketika diminta untuk mencarikan Dewa Siwa obat kedunia. Kisah ini juga merupakan rangkaian dalam kehidupan pandawa yang bersaudara lima orang diantaranya adalah Yudistira, Bima, Arjuna, Nakula dan Sahadewa, dimana Sahadewa yang nantinya akan mampu untuk membersihkan kutukan yang dialami oleh dewi Uma. Sahadewa telah mendapatkan segala macam ujian dan cobaan dalam hidupnya, tetapi karena kethulusannya menjalankan kehidupan di dunia maka akhirnya sahadewa mampu melepaskan kutukan dari Dewi Uma, sehingga Sahadewa diberikan gelar "Suddhamala".

Karya sastra Bali dalam perkembangannya ada beragam. Dari keragaman inilah diantaranya ada beberapa teks yang sama baik dari segi judul, isi, dan pemaknaannya. Geguritan Suddhamala ditemukan dalam bentuk lontar di Pusdok Dinas Kebudayaan dan Pariwisata Bali dimana naskah tersebut merupakan sebuah lontar dengan aksara Bali, Geguritan ini ketika dibaca, ternyata sama dengan yang ada didalam buku Geguritan yang di populerkan oleh bapak Djendra Pura, Ed. Oleh karena itu dapat disimpulkan bahwa bapak Djendra Pura, Ed. menyadur Geguritan tersebut, karena jika dicocokkan, geguritan Suddhamala yang ditulis didalam lontar oleh I Nyoman Tengah dibuat pada tahun 1989 sedangkan buku yang dipopulerkan oleh bapak Djendra Pura, Ed. disusun pada tahun 2003. Dengan adanya kesamaan judul dan isi maka dalam hal ini akan lebih memfokuskan penelitian pada saduran yang dipopulerkan oleh bapak Djendrapura, Ed. yang sudah bertulisan latin.

\section{PEMBAHASAN}

\subsection{Sinopsis Geguritan Suddhamala}

Sinopsis geguritan Suddhamala diawali dari kisah yang ada di Siwaloka, Dewa Siwa akan menguji kesetiaan dari Dewi Uma. Dewa Siwa bermaksud ingin mengetahui apakah Dewi Uma benar-benar setia atau tidak. Maka dari itu Dewa Siwa berpura-pura sakit keras dan tidak bisa disembuhkan. Kemudian Dewi Uma menghadap kepada dewa Siwa dan bersedia mencarikan obat, Dewi Uma bertanya kepada Dewa siwa apakah obat yang bisa menyembuhkan penyakit yang didertita oleh Dewa Siwa. Dewa siwa lalu memberitahu bahwa penyakitnya hanya bisa disembuhkan oleh air susu lembu yang ada di dunia.

Kesetian Dewi Uma membuatnya tidak membuang-buang waktu lagi untuk segera terbag ke dunia dan mencari air susu lembu. Pada saat yang bersamaan Dewa Siwa juga pergi kedunia dan menjelma menjadi pengembala yang memiliki lembu yang sudah memiliki anak, dimana lembu itu banyak memiliki susu.

Lama mencari menyusuri dunia, memasuki hutan dan lain sebagainya akhirnya Dewi Uma bertemu dengan seorang pengembala. Setelah bertemu dengan pengembala itu maka terjadilah negosiasi antara Dewi Uma yang ingin mendapatkan air susu lembu. Dewi uma bersedia membeli dengan harga berapapun dan akan mengganti air susu lembu itu dengan intan dan permata. Tetapi pengembala yang merupakan jelmaan dari Dewa Siwa itu tidak mau menukarnya dengan Intan Permata. Gembala itu mau memberikan air susu itu apabila Dewi Uma mau memenuhi keinginan si pengembala yaitu agar mau melayani keinginannya untuk berhubungan badan. Hal itu tentunya membuat Dewi Uma marah besar kepada si pengembala tersebut.

Pengembala itu tidak pernah mau memberikan 
air susu lembunya walau ditukar dengan intan permata, sampai akhirnya demi cintanya kepada Dewa Siwa, Dewi Uma mau melayani permintaan sang pengembala yaitu berhubungan badan. Setelah selesai berhubungan badan maka Dewi Uma diberikan Air Susu tersebut. Dewi Uma segera membawa air susu lembu itu ke Siwa Loka. Sesampai di Siwa Loka, segera Dewi Uma memberikannya kepada Dewa Siwa untuk berobat. Setelah selesai minum air susu lembu itu Dewa Siwa mengucapkan terimakasih dan menanyakan bagaimanakah Dewi Uma sampai bisa mendapatkan air susu itu. Dewi uma mengatakan bahwa air susu itu didapatkan dengan cara menukarnya dengan intan permata. Tentu hal itu membuat Dewa Siwa marah, karena Dewi uma tidakjujur.

Marahnya Dewa Siwa tidak bisa terhalangi dan langsung mengutuk Dewi Uma agar menjadi Durga dan mengalami hukuman selama dua belas tahun didunia serta diberikan tempat untuk menjaga kuburan Gandamayu sampai akhirnya kutukan itu akan dibebaskan oleh Sang Sahadewa. Disana Dewi Uma juga ditemani para bidadari dan malaikat yang melakukan kesalahan, diantaranya adalah Ni Kalika serta Citranggada dan Citrangseda.

Sesuai dengan perintah Dewi Durga Citranggada dan Citrangseda yang dikutuk menjadi raksasa Kalanjaya dan Kalantaka agar berteman dengan Korawa serta membantu para korawa hingga tiba saatnya dosanya akan dilebur oleh sang Suddhamala atau Sahadewa. Singkat cerita akhirnya Kalanjaya dan Kalantaka bergabung dengan Korawa dan membuat onar serta mengganggu Pandawa, mengetahui hal itu maka Dewi Kunti menghadap Dewi Durga agar mampu membantu mengalahkan raksasa Kalanjaya dan Kalantaka. Dewi Durga bersedia dengan sarat adalah Dewi Kunti memberi persembahan Kambing Merah yang berisi nasi yang ditutupi oleh putranya yang paling kecil yaitu Sahadewa. Tetapi Dewi Kunti menolak karena Sahadewa bukanlah putra kandungnya serta memohon agar memilih diantara Yudistira, Bima dan Arjuna.

Karena tidak ada kesepakatan maka Dewi Kunti yang tidak rela menyerahkan Sahadewa hendak kembali ke Indraprasta, namun ditengah perjalanan Dewi Kunti di rangsuki oleh Ni Kalika atas permintaan Dewi Durga. Sehingga Dewi Kunti berubah menjadi menakutkan dan tanpa disadari Dewi Kunti menyeret Sahadewa yang akan dijadikan tumbal persembahan kepada Dewi Durga. Sesampainya di skuburan Gandamayu Dewi Kunti kembali sadar dan hendak membawa Sahadewa kembali pulang, tetapi lagi-lagi Ni Kalika merangsuki tubuhnya sehingga dengan marah mempersembahkan Sahadewa kepada Dewi Durga.

Sahadewa diikat di pohon rangdu untuk bisa menyucikan kembali segala dosa Dewi Durga agar bisa kembali lagi menjadi Dewi Uma. Tetapi karena memang benar adanya Sang Sahadewa tidak bisa untuk menyucikan kembali Dewi Durga maka Sahadewa rela untuk dibunuh. Hal itu diketahui oleh
Hyang Naradha, yang menyampaikan kepada Dewa Aswino dan Dewa Sangkara serta meneruskannya kepada Dewa Siwa. Mengetahui hal tersebut Dewa

Siwa lalu bergegas untuk pergi ke Kuburan Gandamayu dan mendekati Sang Sahadewa.

Sahadewapun diminta untuk tidak kawatir dan bersedia membantu Dewi Durga menyucikan segala dosanya. Akhirnya Sahadewa mampu menyucikan Dewi Durga serta mampu mengembalikannya kembali menjadi Dewi Uma. Semua Bidadari dan malaikat yang terkena kutukan juga berhasil disucikan, kecuali Sang Kalika yang memiliki dosa terlalu besar karena menyantet dan meracuni suaminya setra Kalanjaya dan Kalantaka yang masih berteman dengan Korawa. Atas keberhasilnya menyucikan dan melebur dosa

Dewi Uma, lalu Dewi Uma memberikan Sahadewa nama yaitu Suddhamala serta memberi hadiah yang berupa jodoh dengan jalan meminta menyembuhkan Bagawan Tamba Petra yang berasal dari Prang Alas. Setelah berhasil menyembuhkan

Bagawan Tamba Petra dari kebutaanya maka Sahadewa diberikan mengambil kedua anaknya yaitu Dewi Soka dan adiknya yang bernama Dewi Padapa.

Setelah lama tidak terdengar kabar beritanya Sahadewa membuat kakaknya Sang Nakula merasa sedih dan berniat untuk menyusulnya sampai pada akhirnya atas petunjuk dari Ni Kalika tibalah juga Nakula di Prang Alas serta mereka berdua sama-sama menikah dimana Nakula menikah dengan Dewi Soka sedangkan Sahadewa menikah dengan Dewi Padapa.

Setelah lama berada di Prang Alas Nakula dan Sahadewa mendengar bahwa Indraprasta diganggu oleh raksasa yang merupakan teman dari Korawa, akhirnya Nakula dan Sahadewa memutuskan kembali ke Indraprasta dengan mengajak istrinya. Sesampai di Indraprasta Sahadewa menceritakan kisahnya sampai ia mendapatkan nama baru yaitu Suddhamala

serta istri untuk Nakula dan dirinya. Tetapi indraprasta masih dalam keadaan waspada karena masih diintai oleh dua raksasa yaitu Kalanjaya dan Kalantaka yang tidak mampu dihadapi oleh Yudistira, Bima dan Arjuna. Nakula dan Suddhamala lalu bersiap menghadapi kedua raksasa itu. Akhirnya kedua raksasa itu bisa dikalahkan oleh Suddhamala.

Setelah dikalahkan tiba-tibaraksasaitu berubah menjadi dua malaikat yang sangat tampan yaitu Citranggada dan Citrangseda serta memberikan anugerah kepada Pandawa agar selalu menang menghadapi musuh-musuhnya. Begitulah ketulusan

dan kepasrahan terhadap Tuhan yang akhirnya mampu menjadi pelebur dosa.

\subsection{Struktur Forma}

Struktur forma merupakan suatu tahapan dalam penelitian yang sangat penting dan sulit dihindari yaitu penelitian struktur. Sebab teori struktur bertujuan untuk membongkar dan memaparkan secermat, seteliti, semendetail dan semendalam mungkin keterkaitan dan keterjalinan semua anasir dan aspek karya sastra yang bersama-sama menghasilkan makna menyeluruh (Teeuw, 1984: 135). Struktur forma adalah salah satu bagian yang tidak 
dapat dipisahkan dari unsur karya sastra itu sendiri, karena struktur forma merupakan struktur luar yang membungkus suatu karya sastra. Struktur forma meliputi: kode bahasa dan sastra, ragam bahasa dan gaya bahasa yang digunakan dalam membangun karya sastra, serta sasmitaning tembang atau isyarat pola persajakan yang terdapat dalam karya sastra geguritan (Karsono, 1988:65).

\subsubsection{Kode Bahasa dan Sastra dalam Geguritan Suddhamala}

Membaca sebuah geguritan tidaklah seperti membaca sebuah prosa pada umumnya, karena dikemas oleh pupuh-pupuh dengan persyaratannya yang lazim disebut pada lingsa. Pada lingsa sebagai sebuah metrum (pola persajakan) atau konvensi merupakan suatu institusi yang mengikat konstruksi suatu geguritan, yang dapat dipahami melalui pemahaman masyarakat pendukungnya. Institusi tersebut selanjutnya berfungsi sebagai kode sastra/ kesusastraan yang dibentuk melalui pengolahan/ modifikasi unsur-unsur bahasa. Dengan demikian, maka kode bahasa dan sastra merupakan metrum/ konveksi suatu karya sastra, yang dalam hal ini adalah geguritan dengan pada lingsanya.

Apabila telah mengetahui pada lingsa dari masing-masing pupuh, maka kode bahasa dan sastra pada Geguritan Suddhamala dapat diketahui dengan mencermati pupuh-pupuh beserta pada lingsanya yang digunakan dalam cerita. Adapun pupuh-pupuh yang digunakan dalam geguritan ini meliputi:

\section{a. Pupuh Sinom}

Menurut tradisi tutur, pupuh ini diperkirakan diciptakan oleh Kanjeng Sunan Giri Kadaton. Sinom secara harfiah berarti (1) pucuk daun muda dan (2) daun muda asam. Kedua makna ini sama-sama mengisyaratkan suatu keadaan usia muda yang penuh dengan keceriaan, penuh cita-cita, dan kemauan. Pemakaian nama Sinom mengisyaratkan bahwa pola persajakan jenis ini mempunyai sifat ceria, ramah, dan menyenangkan (Saputra, 1992:23). Oleh karena itu, pola persajakan Sinom tepat untuk berdialog dengan sahabat, untuk menciptakan cinta kasih, dan untuk menyampaikan nasihat dan amanat. Adapun pada lingsa Pupuh Sinom yang digunakan dalam Geguritan Suddhamala, yaitu:
I : : - . - - - / 8 a
II $\quad:-----/ 8 \mathrm{i}$
III $:-\cdots---/ 8$ a
IV $:-\cdots--1 / 8 \mathrm{i}$
$\mathrm{V} \quad:-\cdots---1 / 8 \mathrm{i}$
VI : - - - - - / / $8 \mathrm{u}$
VII : - - - - - / / $8 \mathrm{a}$
VIII : - - - - - - / / $8 \mathrm{i}$
IX $:---/ 4 \mathrm{u}$
$\mathrm{X} \quad$ :---.--//8a

Penggunaan Pupuh Sinom pada geguritan ini muncul sebanyak satu kali, yaitu sejumlah 22 bait. Mulai dari pembukaan geguritan yang menceritakan Dewa siwa yang bermaksud untuk menguji kesetiaan dewi Uma serta kesediaan Dewi Uma untuk mencarikan Dewa Siwa obat untuk sakitnya sampai akhirnya dikutuk oeleh Dewa Siwa. Berikut kutipan yang menunjukkan hal tersebut:

...//Ngawit mangkin katuturang/ Ida Sang Hyang Giri Putril mapi-mapi sungkan rahat/ kahyun ida mamintonin makadi ida bhataral Bhatari Uma kawuwus/ baktine kalawan nenten/ mugi mangkin ne ungsengin/ Duh dewayu/ mai ja dewa tampakang// (Pupuh Sinom bait 2)

Terjemahannya :

...//Sekarang mulai diceritakan/ yang mulia Dewi Uma/ Pura-puralah sakit keras/ maksudnya untuk menguji begitulah Dewa Siwa/ Untuk menguji Dewi Uma/ apakah berbakti atau tidak/ semoga sekarang bisa dilaksanakan/ Wahai dinda/ marilah dinda mendekat//

Beberapa penyimpangan guru wilangan berupa kekurangan atau kelebihan suku kata pada beberapa bait ditemukan pada Pupuh Sinom ini. Kekurangan suku kata terjadi pada: bait 2 (baris 5), bait 3 (baris 5), bait 9 (baris 5), bait 10 (baris 7), bait 17 (baris 7), dan bait 20 (baris 7) yang sama-sama kekurangan satu suku kata. Kelebihan suku kata terjadi pada: bait 5 (baris 2), bait 6 (baris 5), dan bait 16 (baris 7) yang sama-sama kelebihan satu suku kata. Kesalahan ding-dong juga terjadi pada bait 2 (baris 5 dan 7) Penyimpangan pada guru wilangan dan ding dong tersebut merupakan suatu ketidaksengajaan atau kelengahan. Berikut tabel penjabaran pupuh sinom secara keseluruhan dalam geguritan Suddhamala.

\section{b. Pupuh Ginadha}

Pupuh Ginada diperkirakan lahir di Bali, yang biasanya digunakan untuk melukiskan kesedihan, kemeranaan atau kekecewaan. Pupuh ini memiliki berbagai variasi tembang, seperti: ginada basur, ginada bungkling, dan sebagainya. Namun, yang digunakan dalam Geguritan Suddhamala adalah ginada basur dan ginada yang lumrah/umum. Adapun pada lingsanya yang juga digunakan dalam geguritan ini, yaitu:

I : - . . - - / / a

II : - - - - - - / / 8i

III : - - - - - / 8a

IV : - . . - - / / $8 \mathrm{u}$

$\mathrm{V} \quad:-\cdots-1 / 8 \mathrm{a}$

VI : - - - / / i

VII : - - - - - - // 8a

Penggunaan Pupuh Ginadha pada geguritan ini dimunculkan sebanyak dua kali. Pertama, Pupuh Ginadha Basur dengan jumlah 22 bait digunakan ketika menceritakan hukuman yang diterima oleh Dewi Uma untuk berubah wujud menjadi Durga sampai kedatangan Dewi Kunti untuk meminta bantuan kepada Dewi Durga untuk menghadapi raksasa Kalanjaya dan Kalantaka

...//Seos mangkin caritayang/ wenten widyadara kekalih/ medal ida sinarengan/ Citranggada kawuwus/ miwah Sang Citraseda/ sareng kalih/ Hyang Guru ida nyupat// ( Pupuh Ginada Bait 1) 
Terjemahannya :

...//Lain sekarang diceritakan/ ada widyadara berdua/ keluar beliau bersama/sama/ bernama Citranggada/ serta Citraseda/ berdua/ mereka dikutuk oleh Bhatara Guru//

Pemakaian Pupuh Ginadha Basur ini terdapat penyimpangan terhadap guru wilangan berupa kelebihan satu suku kata yang terjadi pada bait 2 (baris 4), bait ke 7 (baris ke 3), bait ke 9 (baris 7). Selain itu, dijumpai juga penyimpangan terhadap kurangnya satu suku kata juga terdapat pada bait 1 (baris 4,5,7), bait 2 (baris 7) bait 5 (baris 7) bait 6 (baris 3). Adanya penyimpangan tersebut kemungkinan merupakan keteledoran pengarang dalam membuat pupuh sesuai dengan aturan-aturan yang berlaku.

Pupuh Ginadha yang kedua merupakan Ginada Dasar yang berjumlah 24 bait digunakan untuk menceritakan Sahadewa ketika sudah dipersembahkan kepada Dewi Durga sampai akhirnya berita kemarahan Dewi Durga sampai kepada Dewa Siwa. Total penggunaan Pupuh Ginada pada geguritan ini adalah berjumlah 46 bait. Berikut kutipan Pupuh Ginada tersebut.

...//Wenten Sane itep pisan/ manabdabang basang bangkel wenten sane mukangmukang/ miwah melut tendas ditu/ ne pecak sampun matanem/ tios malih/ dingkrakdingkrak ipun ngigel// (Pupuh Ginada bait 25) Terjemahannya :

...//Ada yang serius sekali/ memainkan perut bangkai/ ada yang memotong-motong/ juga mengupas kepala disana/ yang sudah dikubur/ lain lagi/jingkrak-jingkrak mereka menari-nari//

Penyimpangan guru wilang pada Pupuh Ginadha ini terjadi pada: bait 23 (baris 3), bait 24 (baris 7), dan bait 25 (baris 3) dimana terjadi kelebihan suku kata. Kekurangan suku kata juga ditemukan pada Pupuh Ginada bait 24 (baris 6), bait 26 (baris 3 dan 7), bait 27 (baris 6), bait 33 (baris 2 dan 5) Hal ini terjadi karena kekurangan atau kelebihan suku kata saat di lantunkan boleh menambahkan huruf vokal atau menguranginya ditengah-tengah.

\section{c. Pupuh Durma}

Pupuh Durma diperkirakan merupakan karangan dari Sunan Bonang yang biasanya digunakan untuk mengisyaratkan hal-hal buruk, seperti: peperangan, kekacauan, dan sebagainya (Saputra, 1992:27). Adapun pada lingsa Pupuh Durma yang digunakan dalam Geguritan

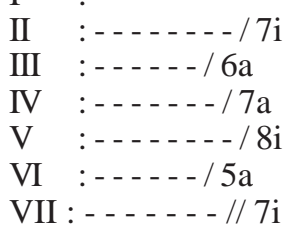


yang sama-sama kelebihan satu suku kata. Penyimpangan pada guru wilangan tersebut merupakan suatu ketidaksengajaan atau kelengahan.

\section{d. Pupuh Semarandana}

Pupuh Smarandana konon diciptakan oleh Kanjeng Sunan Giri Kadaton. Kata smarandana merupakan paduan kata semara dan dana. Semara memiliki arti asmara atau cinta, sedangkan dana sendiri merupakan kependekan dari dahana yang berarti api. Jadi, kata semarandana berarti api asmara. Demikianlah makna pola persajakan yang bernama semarandana ini mempunyai sifat sedih, suatu kesedihan akibat dirundung api asmara, sehingga jenis pola pada lingsa ini sesuai untuk mengungkapkan isi wacana yang bermakna rindu dendam asmara atau untuk merayu (Dewi, 2012:59). Adapun pada lingsa Pupuh Semarandana yang digunakan dalam Geguritan Suddhamala, yaitu:

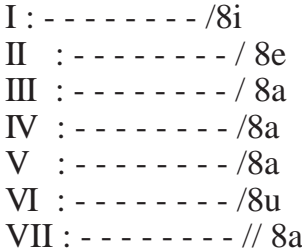

Penggunaan Pupuh Semarandana dalam geguritan ini juga hanya dimunculkan satu kali saja. Jumlah bait yang digunakan sebanyak 18 bait. Isinya menceritakan turunnya Dewa Siwa menuju Gandamayu untuk memberikan Sahadewa anugerah agar mampu menyucikan dosa Dewi Durga serta Dewi Durga memberikan nama Suddhamala kepada Sahadewa sampai persiapan perjalanannya menuju Prang Alas Berikut kutipan yang menunjukkan hal tersebut.

...//Hyang Uma raris mamargi/ nampokin Sang Sahadewa/ tumuli ngandika alon/ Uduh cening Sahadewal meme dahating suksmal baan legan i cening bagus/ malan meme sida ruwat// (Pupuh Smarandana bait 11)

Terjemahannya :

...//Dewi uma lalu berjalan/ mendekati

Sahadewa/ lalu berbicara pelan/ wahai anakku Sahadewa/ ibu sangat berterimakasih/ karena kemauan anakku/ dosa ibu bisa disucikan// Beberapa penyimpangan dalam Pupuh Semarandana dalam geguritan ini terjadi pada guru wilangan berupa kekurangan satu suku kata yang terdapat pada: bait 3 (baris 5), bait 6 (baris 5), bait 9 (baris 4), dan bait 10 (baris 3). Adanya penyimpangan tersebut kemungkinan karena unsur ketidaksengajaan/kelengahan dari pengarang.

\section{e. Pupuh Pangkur}

Pupuh ini diperkirakan karangan Sunan Muria. Pangkur berasal dari kata "kur" yang kemudian membentuk kata-kata seperti: pungkur, singkur, kukur, dan mungkur yang kesemuanya mengandung makna belakang (Dewi, 2012:52). Pupuh pangkur biasanya digunakan untuk menyatakan perasaan hati dan suasana yang sungguh-sungguh/puncak
(Saputra, 1992:29). Adapun pada lingsa Pupuh Pangkur yang digunakan dalam Geguritan Suddhamala, yaitu:

I : - .-.- $18 \mathrm{a}$

II $\quad:------/ 10 \mathrm{i}$

III : - - - - - / /

IV :- - - - / / a

$\mathrm{V}:-\cdots-\cdots / 12 \mathrm{u}$

VI : : - . - - /

VII :- - - - - // 8i

Pada geguritan ini, Pupuh Pangkur digunakan hanya sekali. Dalam geguritan ini menggunakan pupuh pangkur sebanyak 30 bait yang digunakan untuk menceritakan perjalanan Sang Suddhamala menuju Prang Alas untuk menyucikan dan menyembuhkan Rsi Tamba Petra sampai pada akhirnya Suddhamala akan kembali lagi menuju Indraprasta. Berikut kutipan pupuh tersebut.

...//Sang Sudamala mamarga/ tur manyujur/ ngaja kanginang mangungsi/ munggah bukit tedun pangkung/ nyusup alas madurgamal sakewala tanana ngardi pakewuh/ tan warnanen ada ring awak/ rauh ring Prang Alas manukin// (Pupuh Pangkur bait 1)

Terjemahannya :

...//Sang Suddhamala berjalan/ dan menuju/ ke arah timur laut/mendaki bukit menuruni lembah/ menyusuri hutan yang menyeramkan/ tetapi tidak ada yang membuat susah/ Tak terceritakanlah dirinya/ sekarang tiba di Prang Alas//

Beberapa penyimpangan guru wilangan ditemukan pada Pupuh Pangkur I berupa kekurangan dan kelebihan suku kata pada beberapa bait. Kekurangan suku kata terjadi pada: bait 1 (baris 2), bait 2 (baris 4), dan bait 13 (baris 4) yang samasama kekurangan satu suku kata. Kelebihan satu suku kata terjadi pada: bait 1 (baris 2) dan bait 14 (baris 2). Kelebihan dua suku kata terjadi pada: bait 2 (baris 2) dan bait 27 (baris 2). Penyimpangan pada guru wilangan tersebut merupakan suatu ketidaksengajaan/kelengahan dari pengarang.

\section{f. Pupuh Dangdang Gula}

Menurut tradisi tutur, Pupuh Dangdang gula digunakan untuk menguraiakan kelembutan hati. Adapun pada lingsa Pupuh Ginanti yang digunakan dalam Geguritan Suddhamala, yaitu:

I : :- - - - - / / $10 \mathrm{i}$

II $:---/ 4 a$

III $:----/ 6 a$

IV $:-\cdots---18 \mathrm{i}$

$\mathrm{V} \quad:-\cdots--1 / 8 \mathrm{u}$

VI $:-\cdots---1 / 8 \mathrm{i}$

VII : - - - - - - // 8a

VIII : - - - - - - // 8u

IX : :--.-- // $8 \mathrm{a}$

$\mathrm{X}:-\cdots / / 4 \mathrm{a}$

XI :--.---//8i

XII : - - - - - - //8a

Penggunaan Pupuh dangdang gula hanya muncul satu kali dengan jumlah sebanyak 15 bait, 
yang digunakan menceritakan keberadaan Nakula dan Suddhamala di Prang Alas dimana di Indraprasta Yudistira, Bima dan Arjuna kesulitan menghadapi Kalanjaya dan Kalantaka sampai akhirnya Nakula dan Suddhamala memutuskan kembali ke Indraprasta, yang di antaranya termuat dalam kutipan berikut:

...//Jalan jani beli adi mamargi/ makamuka/ ngendonin Pandhawal sang karo sahasa mangkin/ kadulurin saha tabuh/ maka pagalak ipun sami/ maduluran panjak katah/ makasami girang ngelurl pangungsi Pandhawa kulal sampun tatas/ Sang Pandhawa maring indik/ pidabdab i detia karua// (Pupuh Dangdang gula bait 6)

Terjemahannya :

...//Marilah sekarang kira berjalan/ bertanding/ mendatangi Pandawa/ Disertai dengan suara tabuh/ sebagai penyemangat mereka semua/ disertai prajurit yang banyak/ semuanya senang berteriak-teriak/ menuju ke tempat keluarga Pandawa/ sudah jelas/ Sang pandawa terhadap keadaan/ perilaku kedua raksasa tersebut//

Penyimpangan guru wilangan juga ditemukan pada penggunaan Pupuh Ginanti ini berupa kelebihan suku kata yang terjadi pada bait 1 (baris 4 dan 6), bait 2 (baris 7), bait 8 (baris 9 dan 11), bait 13 (baris 7 dan 11). Adanya penyimpangan tersebut kemungkinan karena unsur ketidaksengajaan atau kelengahan dari si pengarang.

Geguritan Suddhamala terdiri dari 182 bait pupuh dimana pupuh Sinom terdiri dari 22 bait, pupuh ginada terdiri dari 46 bait, pupuh durma sebanyak 51 bait, pupuh semarandana terdiri dari 18 bait, pupuh pangkur 30 bait dan pupuh dangdang gula sebanyak 15 bait. Dimana bait-bait tersebut memberikan warana dan keragaman dalam geguritan ini.

\subsubsection{Ragam Bahasa}

Ragam bahasa merupakan model penggunaan bahasa dalam teks, dalam hal ini menyangkut variasi bahasa menurut pemakaian dan penggunaannya (Jendra, 1981: 49). Menurut Kridalaksana (dalam Granoka, 1991: 17) menyebutkan ragam Bahasa merupakan variasi Bahasa menurut pemakainya, berdasarkan topik yang dibicarakan, hubungan pembicara, lawan bicara dengan orang yang dibicarakan dan berdasarkan medium pembicaraan. Bahasa Bali yang digunakan oleh masyarakat Bali bertujuan untuk berkomunikasi secara lisan dan tulisan. Bentuk komunikasi secara tertulis memakai Bahasa Bali terdapat dalam karya sastra geguritan, seperti Geguritan Suddhamala

Bahasa Bali dalam fungsinya memiliki berbagai macam tingkatan berdasarkan maknanya dalam kehidupan sosial masyarakat Bali. Tingkatan kehidupan sosial masyarakat Bali, dipengaruhi oleh wangsa yang berkembang di Bali. Wangsa ini dibedakan menjadi empat wangsa disebut dengan catur wangsa yakni Brahmana, satria, wesia, dan jaba. Golongan Brahmana, satria, dan wesia disebut golongan menak atau triwangsa.

Berdasarkan adanya tingkatan kehidupan sosial dalam masyarakat Bali, maka tingkatan ragam pemakaian Bahasa Bali dapat dibedakan menjadi tiga kelompok yakni : ragam basa Bali alus, ragam basa Bali madia, ragam basa Bali Kasar. Sistem ini disebut pula Anggah Ungguhing Basa Bali yakni sebuah ragam Bahasa Bali yang pemakaiannya ditentukan oleh peran-peran pelaku penuturnya yang dipengaruhi oleh perbedaan golongan wangsanya. Ragam basa Bali alus dalam pemakaiannya memiliki nilai rasa yang paling tinggi, karena ragam ini dianggap ragam Bahasa Bali yang tutur bahasanya paling halus. Ragam basa Bali alus dalam fungsinya dapat dibedakan menjadi empat yakni basa Bali alus singgih, basa alus sor, basa alus madia dan basa alus mider (Tinggen, 1993: 10).

Ragam basa Bali madia merupakan ragam Bahasa yang nilai rasa dalam pemakaiannya di anggap paling lumrah atau biasa-biasa, karena tidak adanya sikap yang perlu ditunjukkan, baik sikap hormat atau merendah, namun pemakaiannya cukup sopan dalam masyarakat. Sedangkan ragam basa bali kasar adalah ragam Bahasa yang nilai rasanya dianggap paling rendah dalam pemakaiannya. Penggunaan ragam Bahasa ini hampir sama dengan ragam basa madia, dan sangat tergantung pada situasi komunikasinya (Granoka, 1991:33).

Ragam Bahasa yang terdapat dalam Geguritan Dharma Sunyata ditentukan berdasarkan tingkatan penuturnya. Geguritan Dharma Sunyata merupakan sebuah karya sastra yang berisikan dialog yaitu antara guru dan murid, serta murid dengan gurunya. Adapun ragam Bahasa yang terdapat dalam Geguritan Suddhamala adalah ragam Bahasa Bali dan digunakan juga Bahasa Kawi pada pembukaan Geguritan Suddhamala yakni pada pupuh Durma, sebagai berikut

\section{a. Basa Bali Alus}

Basa Bali Alus merupakan ragam Bahasa Bali yang memiliki nilai rasa paling hormat dan sopan dalam pemakaiannya. Penggunaan basa Bali alus dalam masyarakat Bali disebabkan karena adanya perbedaan identitas antara pembicaraan dengan lawan bicara. Basa Bali Alus dalam tingkatan Bahasa Bali yang mempunyai rasa Bahasa yang tinggi atau sangat hormat biasanya digunakan dalam situasi resmi, seperti: rapat, pertemuan, seminar, sarasehan, percakapan mengenai adat, agama dan sebagainya (Suarjana, 2010: 105). Adapun ragam basa Bali alus yang dipergunakan dalam Geguritan Suddhamala dapat dilihat dalam kutipan berikut ini:

....//Bhatara Siwa angucap/ wacanane sada aris/ Mawosang sungkane rahat/ bhatari sarwi nyaurin/ Naweg titiang nene mangkin/ antuk nambete kalintang/ napi anggen titiang tamba/ tan kamanahan antuk mangkin/ inggih ratu/ durusang titiang nikayang// (Pupuh Sinom bait 4) 
Terjemahannya :

...//Dewa siwa berkata/ perkataanya sangat pelan/ mengatakan sakitnya sangat berat/ kemudian dijawab oleh Dewi Uma/ hamba sekarang memohon ijin/ karena saya sangat bodoh/ apa yang saya pakai obat/ tidak terpikirkan oleh saya/ baiklah kanda/ sampaikanlah kepada saya//

Pada kutipan pupuh diatas dijelaskan ragam Bahasa yang digunakan menggunakan basa Bali alus, dalam hal ini memuat percakapan antara Dewa Siwa dengan Dewi Uma, Dewi Uma dengan I Pengangon, Dewi Kunti dengan Dewi Durga, Bima Dengan Dewi Kunti, Suddhamala dengan Dewi Durga, Suddhamala dengan I Patut, Suddhamala dengan Rsi Tamba Petra. Basa Bali alus ini dipakai ketika berbicara dengan orang yang lebih tua apalagi yang diajak bicara adalah seorang ibu, orang suci serta orang yang baru pertama kali diajak berkomunikasi. Menggunakan basa Bali alus adalah menghormati orang yang lebih tua dan menghormati orang yang baru dikenal seperti melaksanakan sopan santun dalam berbicara.

\section{b. Basa Bali Madia}

Basa Bali Madia merupakan ragam Basa Bali yang lumrah dipakai di kalangan masyarakat Bali. Ragam ini memiliki nilai rasa yang sedang dalam pemakaiannya, yaitu tidak terlalu halus dan tidak terlalu kasar. Menurut Tinggen (1993: 11) basa Bali madia disebut juga basa kesamen atau kepara. Ragam Bahasa Lumrah yang bisa dipakai oleh semua kalangan masyarakat serta tidak mengandung nilai rasa untuk hormat atau kasar. Pemakaian ragam basa Bali madia dalam Geguritan Suddhamala, dipakai dalam berbagai hal, yaitu dapat dilihat dalam kutipan pupuh berikut ini:

...//Ne jani durus pirengang/ beli katiban gering/ gring bli rahat pisan/ gring kantane mabalik/Wawu miarsa bhatari/ wedanane ngetus kayun/ Bhatari glis ngarepang/ madulur ngaturang baktil Inggih ratu/ ampurayang dewek titiang// (Pupuh Sinom bait 3)

Terjemahannya :

Sekarang dengarkanlah/ kanda terkena penyakit/ penyakit kanda sangat berat/ sakit kerongkongan terbalik/ Barulah didengar oleh Dewi Uma/ Wajahnya sangat sedih mengiris hati/ Dewi uma segera mendekat/ Serta memberikan hormat/ "Baiklah kanda/ maafkanlah diri ini/

Salah satu kutipan pada pupuh Sinom di atas dalam percakapan Dewa Siwa dengan Dewi Uma, penggunaan kalimat tersebut rasa Bahasa Bali yang digunakan datar-datar saja. Penggunaan Basa Bali Madia digunakan pada kutipan ini, terlihat pada penggunaan kalimat "ne jani" yang berarti "sekarang" dalam penggunaan anggah ungguhing Basa Bali kata tersebut bisa dipakai dalam setiap kalangan. Golongan Tri Wangsa bisa juga digunakan kata tersebut dalam percakapan.

...//Bhatara Siwa ngandikal Kema luas ka mrecapadha/ ne buat ento alih/ empehan lembu putih/ sig anake ngangon lembu/ saget sida adi maan/ buatang kema adi alih/ pade durung/ eda adi malipetan// (Pupuh Sinom bait 5)

Terjemahannya :

...//Dewa siwa memerintahkan/kesana dinda turun ke Bumi/ yang diperlukan tolong dicari/ susu lembu putih/ di tempat orang mengembalakan lembu/ siapa tahu dinda mendapatkan/ utamakan untuk mencari kesana/ kalau belum dapat/ janganlah dinda kembali// Kutipan tersebut menggunakan Basa Bali

Madia, ditemukan pada penggunaan kalimat "ne buat ento alih" yang berarti yang diperlukan itu cari. Kalimat "ne buat ento alih" rasa basa Bali yang digunakan semua bisa terwakili. Kalimat tersebut bukan hanya digunakan untuk menyebutkan golongan sudra tetapi semuanya bisa memakai kata tersebut.

.../Pradnyan ida ring payudan/ ida patut nglukat nyail apang kadi jati mulal nah ngawit dina ne jani/ teka ditu jani malinggih/ maring setra Gandamayu/ kairing baan $\mathrm{Ni}$ Kalikal panjroan ida adiril gelis mabur/ Gandamayune ungsiang// (Pupuh Sinom bait 22)

Terjemahannya :

...//Sangatlah pintar beliau berperang/ beliau yang berhak menyucikanmu/ agar bisa seperti semula/baiklah mulai hari ini/disanalah engkau tinggal/di kuburan/ diiringi oleh Ni Kalika/satu orang dayang milikmu/ segera pergi/ menuju Kuburan//

Kutipan tersebut pada kalimat "nah ngawit dinane jani" berarti "baiklah, mulai saat ini" dan rasa Basa yang digunakan pada kalimat tersebut bersifat datar. Bisa digunakan pada semua kalangan. ...//Disubane roras tiban/ kala ditu buin mawali/ bareng tekening manira/ nah jani antiang malu/ sengkere roras tiban/ ane jani/ kema lunga ka Astina// (Pupuh Ginada bait 8)

Terjemahannya :

...//Setelah dua belas tahun/ saat itu kembali lagi/ bersama/sama dengan saya/ baiklah sekarang tunggu dulu/ batas waktu duabelas tahun/ sekarang/ pergilah ke Astina//

Penggalan pupuh ginada pada kutipan tersebut menggunakan Basa Bali Madia, terlihat dalam penggunaan kalimat "disubane roras tiban" yang berarti "setelah dua belas tahun". Rasa Basa yang digunakan biasa-biasa saja, kalimat tersebut dalam penggunaannya semua kalangan bisa disebutkannya. Bukan hanya kaum Brahmana saja tetapi bisa semuanya termasuk kaum jaba.

...//Hyang Durga raris nakenang/Nyen musuh Pandawane Kunti/ Singgih Ratu Hyang 
Durga/mungguing wastannya i satru/tan seos Sang Kalanjaya/ malih siki/ mawasta Sang Kalantaka// (Pupuh Ginada bait 17) Terjemahannya :

...//Dewi Durga lalu bertanya/ Kunti, Siapa musuh pandawa/ Baiklah Dewi Durga/ namanya sang musuh/ tan lain adalah sang kalanjaya/ lagi satu/ bernama sang kalantaka//

Penggalan pupuh ginada pada kutipan tersebut menggunakan Basa Bali Madia, terlihat dalam penggunaan kalimat "nyen musuh Pandawane Kunti" yang artinya "Kunti, siapa musuh Pandawa" Rasa Basa yang digunakan biasa-biasa saja, kalimat tersebut dalam penggunaannya semua kalangan bisa disebutkannya. Bukan hanya kaum jaba saja tetapi bisa semuanya termasuk kaum brahmana. Bahasa yang digunakan netral tidak terlalu halus juga tidak terlalu kasar.

...//Enggalang ja alih pianake Sang Sahadewal kema alih ajak mail sapunika Dewi Durga/ Dewi Kunti tan pasabdal reh kahyunne banget paling/ digelis budal/ midarta ring putrasami// (Pupuh Durma bait 6)

Terjemahannya :

...//Segeralah cari anakmu sang Sahadewa/ kesana cari bawa kemari/ begitulah dewi durga/ Dewi kunti tanpa berbicara/ karena hatinya sangat gundah/ segera pergi/ berkata kepada semua putranya//

Penggalan pupuh durma pada kutipan tersebut menggunakan Basa Bali Madia, terlihat dalam penggunaan kalimat "kema alih ajak mai" yang berarti "kesana cari bawa kemari". Rasa Basa yang digunakan biasa-biasa saja, kalimat tersebut dalam penggunaannya semua kalangan bisa disebutkannya. Dipergunakan dalam Bahasa pergaulan sehari-hari dimana rasa basa itu datar dimana itu merupakan bahasa alus madia.

.../Saget sampun napak mangkin/ maring setra Gandamayu/ sarwi mangandika mangkol majeng ri Sang Sahadewal Uduh cening pianak bapa/ melah ne jani $i$ bagus/ ngruat malan Nini Durgall (Pupuh Semarandana, bait 2)

Terjemahan :

...//Tiba-tiba sekarang sudah sampai/ di kuburan Gandamayu/ serta berkata sekarang/ kepada Sang Sahadewa/ Wahai anakku/ lebih baik sekarang ananda/ menghilangkan dosa Dewi Durga//

Penggalan pupuh semarandana pada kutipan tersebut menggunakan Basa Bali Madia, terlihat dalam penggunaan kalimat "melah ne jani I bagus" yang berarti "lebih baik ananda sekarang". Rasa Basa yang digunakan biasa-biasa saja, kalimat tersebut dalam penggunaannya semua kalangan bisa disebutkannya. Dipergunakan dalam Bahasa pergaulan sehari-hari dimana rasa basa itu datar dimana itu merupakan bahasa alus madia. .../Jalan jani adi mamargi/ makamukal ngendonin Pandhawal sang karo sahasa mangkin/ kadulurin saha tabuh/ maka pagalak ipun sami/ maduluran panjak katah/ makasami girang ngelurl pangungsi Pandhawa kulal sampun tatas/ Sang Pandhawa maring indik/ pidabdab i detia karual/ (Pupuh Dangdang Gula bait 6)

Terjemahannya :

.../Marilah sekarang adikku berjalan/ bertanding/ mendatangi Pandawa/ Disertai dengan suara tabuh/ sebagai penyemangat mereka semua/ disertai prajurit yang banyak/ semuanya senang berteriak-teriak/ menuju ke tempat keluarga Pandawa/ sudah jelas/ Sang pandawa terhadap keadaan/ perilaku kedua raksasa tersebut//

Penggalan pupuh dangdang gula pada kutipan tersebut menggunakan Basa Bali Madia, terlihat dalam penggunaan kalimat "Jalan jani adi memargi" yang berarti "marilah adik sekarang berjalan". Rasa Basa yang digunakan biasa-biasa saja, didalam berbicara satu keluarga misalnya saudara maka Basa Alus Madia bisa digunakan. kalimat tersebut dalam penggunaannya semua kalangan bisa disebutkannya. Dipergunakan dalam Bahasa pergaulan sehari-hari dimana rasa basa itu datar dimana itu merupakan bahasa alus madia.

\section{c. Basa Bali Kasar}

Ragam basa Bali kasar merupakan ragam Bahasa yang dipakai dalam kehidupan sehari-hari di dalam masyarakat Bali. Tinggen (1993: 12) menjelaskan bahwa Bahasa ini adalah ragam Bahasa yang biasa digunakan untuk berkomunikasi dengan teman yang sudah dekat dan disaat ada pertengkaran. Penggunaan Basa Bali Kasar sesungguhnya hampir sama dengan ragam Basa Bali Madia, dan sangat tergantung pada situasi komunikasinya (Granoka, 1991:33).

Ragam basa Bali kasar pada umumnya memiliki dua nilai rasa, yakni sopan dan tidak sopan. Nilai rasa sopan umumnya digunakan oleh wangsa yang lebih tinggi bila berbicara kepada wangsa yang lebih rendah, orang yang lebih tua berbicara kepada orang yang lebih muda, seorang pimpinan kepada pesuruhnya, orang tua kepada anaknya, berbicara dengan kawan akrab, dan lain-lain. Sedangkan ragam basa Bali kasar yang tidak sopan dipergunakan dalam keadaan tidak wajar kepada orang yang dianggap lawan, misalnya orang marah, mencaci maki dan mengumpat (Tim Peneliti Fakultas Sastra UNUD, 1978/1979: 50). Penggunaan basa Bali kasar yang terdapat dalam Geguritan Suddhamala merupakan ragam basa Bali kasar yang masih memiliki rasa kesopanan yang disampaikan oleh sang guru kepada muridnya. Penggunaan basa Bali kasar yang dimaksud dapat dilihat dalam beberapa kutipan pupuh berikut ini : 
.../Ih ne cai sanget degag/ tusing ke nawang cail Gelah Bhatari Umal Hyang Siwa nganggen rabil ida ane ngutus mail apanga cai tatas taul $i$ pangangon raris nimbal/ Diastune jero dewan bhatari/ tan kaatur// Yan tan nagingin manah titiang// (Pupuh Sinom bait 13)

Terjemahannya :

...//Eh engkau sangat berani/ tidakkah engkau tahu/ saya adalah Dewi Uma/ Dewa Siwa yang menjadikan istri/ beliau yang mengutus kesini/ agar engkau jelas tahu/ Si pengembala lalu menjawab/ walaupun engkau istrinya Dewa Siwa/ tidak akan aku berikan/ kalau tidak memenuhi hasrat saya//

Penggalan pupuh sinom pada kutipan tersebut menggunakan Basa Bali Kasar, terlihat dalam penggunaan kalimat "Ih ne cai sanget degag" yang berarti "Eh engkau sangat berani". Rasa Basa yang digunakan bersifat kasar dan mengarah pada ketidak sopanan. Bahasa seperti itu biasanya digunakan berbicara ketika marah kepada orang yang tidak disukai, karena kalimat"Ih cai" dalam Bahasa Bali masih ada yang memiliki rasa basa lebih halus yakni kalimat "uduh jerone" Penggunaan basa Bali kasar dalam kutipan tersebut tidak dalam Bahasa Bali yang sopan, karena digunakan oleh orang yang kecewa karena lawan bicaranya tidak sopan kepadanya, maka dikeluarkanlah kalimat kasar itu.

...//Dewi Kunti manulak laut matinggal/ ento mawinan nyail jani enggalang jua tut ial tur rangsukin deweknyal Ni Kalika ngetut gelis/ tur masurupan/ maring anggen Dewi Kunti// (Pupuh Durma bait 4)

Terjemahannya :

...//Dewi kunti berjalan lalu pergi/itu sebabnya engkau/ segeralah ikuti dia/ lalu masuklah/ didalam tubuh Dewi Kunti//

Penggalan pupuh durma pada kutipan tersebut menggunakan Basa Bali Kasar, terlihat dalam penggunaan kalimat "Ento Nyai". Rasa Basa yang digunakan bersifat kasar tetapi masih sopan. Karena penggunaan basa Bali kasar dalam kutipan tersebut masih dalam Bahasa Bali yang sopan, karena digunakan oleh orang yang lebih tua (Ratu) kepada yang berkasta lebih rendah (pembantunya). Ketika pembantunya yang memakai Bahasa Bali yang seperti tersebut baru tidak dibolehkan karena dari segi etika berbicaranya tidak sopan kedengarannya. ...//Rauh $i$ bhuta papeteng/ matane bunter abesik/ teka ia gerak-gerak/ ngraos ia sami guyu/ Jani payu nadah ksatria/ nyambal ati/ getihnyane daar corot// (Pupuh Ginada bait 28)

Terjemahannya :

...//Datang si Butha kegelapan/ matanya bulat hanya satu/datang ia berteriak-teriak/ berbicara ia dengan lelucon/ sekarang jadi makan kesatria/ memakan hatinya/ darahnya akan diminum//
Penggalan pupuh ginada pada kutipan tersebut menggunakan Basa Bali Kasar, terlihat dalam penggunaan kalimat "Jani payu nadah ksatria/ nyambal ati, getihnyane daar corot" yang berarti "sekarang jadi makan kesatria, memakan hatinya, darahnya akan diminum". Rasa Basa yang digunakan bersifat kasar dan tidak sopan. Karena kata "payu”, "nyambal", "daar", "corot" dalam Bahasa Bali merupakan bahasa yang sangat kasar sekali. Penggunaan basa Bali kasar dalam kutipan tersebut merupakan dalam Bahasa Bali yang tidak sopan, karena digunakan oleh seorang raksasa (wangsa bawah) kepada pangeran (tri wangsa).

...//Yening saja tuara nyak/ sing buungan cai matil sarwi mangayatang blakas/ jaga manyempal gulu/ Singgih Ratu Hyang Durga/ durus mangkin pademang ratu titiang// (Pupuh Ginada bait35)

Terjemahannya :

...//Kalau benar tidak mau/ pastilah engkau akan mati/ serta mengangkat pedang/ akan memenggal/ Baiklah yang mulia Dewi Durga/ silahkan bunuh saya sekarang//

Penggalan pupuh ginada pada kutipan tersebut menggunakan Basa Bali Kasar, terlihat dalam penggunaan kalimat "Yening saja tuara nyak" yang berarti "kalau benar tidak mau". Rasa Basa yang digunakan bersifat kasar dan tidak sopan. Penggunaan basa Bali kasar dalam kutipan tersebut masih dalam Bahasa Bali yang tidak sopan, karena digunakan ketika hati sedang emosi dan tidak bisa menahan diri. Dewi Durga yang masih dalam keadaan terkutuk dan memiliki sifat keraksasaan maka akan bersifat kasar.

...//Sing buungan cai amah kail ih Arjunal raris ida makilesan/ antuk wisesan mesehel sang bhima raris kacunduk/ Mirib suba lesu adi nah lawut adi kirigang/ beli jani mangamuk/ nandingin I Kalanjayal Sada egar/ Sang Bhima raris mamargi/ manyujur ka payudan// (Pupuh Dangdang Gula bait 12) Terjemahannya :

...//Tidak mungkin tidak sekarang kamu akan saya makan/He arjuna/ lalu beliau menghindar/ karena saktinya musuhnya/ Sang bima lalu bertemu/ mungkin kamu sudah lesu adikku/ segeralah kamu mundur/ sekarang kakak yang akan mengamuk/ melawan I Kalanjaya/ sangat percaya diri/Sang Bima lalu berjalan menuju ke medan peperangan//

Penggalan pupuh dangdang gula pada kutipan tersebut menggunakan Basa Bali Kasar, terlihat dalam penggunaan kalimat "sing buungan cai amah kai" yang berarti "tidak mungkin tidak sekarang kamu akan saya makan". Rasa Basa yang digunakan bersifat kasar dan tidak sopan. Karena kalimat "sing buungan cai amah kai" dalam Bahasa Bali sangatlah kasar, biasanya digunakan pada saat akan bertengkar dengan musuh. 
.../Nuli ngandika Ida Sang Dharma Putra/ Sang Bhima Arjuna nyarengin/ Uduh adi ajak dadua/ uli kija mara teka/ Sang Bhima nimbal nakenin/ Uli dija mara mulih// (Pupuh Durma bait 29)

Terjemahannya :

..../Lalu berkata sang Darmawangsa/ Sang Bima dan Arjuna mengikuti/ Wahai adik-adik berdua/ darimana saja baru datang/ Sang bima lanjut bertanya/ darimana baru pulang//

Penggalan pupuh maskumambang pada kutipan tersebut menggunakan Basa Bali Kasar, terlihat dalam penggunaan kalimat "uli dija mara teka" yang berarti "darimana saja kok baru datang". Rasa Basa yang digunakan bersifat kasar tetapi masih sopan. Penggunaan basa Bali kasar dalam kutipan tersebut masih dalam Bahasa Bali yang sopan, karena digunakan oleh sang kakak kepada adiknya dalam komunikasi etikanya masih dirasakan memiliki rasa kesopanan.

\subsubsection{Gaya Bahasa}

Keberadaaan gaya bahasa jika dihubungkan dengan struktur (bentuk) karya sastra mempunyai peranan yang cukup penting. Seorang pengarang yang tampil akan memanfaatkan bahasa untuk menciptakan nada dan suasana yang tepat guna, sehingga dapat memukau pembaca. Tarigan (1985: 5) menyatakan bahwa secara umum pengertian gaya Bahasa adalah cara mengungkapkan pikiran melalui Bahasa secara khas, sebagai refleksi dari jiwa dan kepribadian penulis (pemakai Bahasa) yang di dalamnya terdapat unsur kejujuran, sopan santun, dan menarik. Pemakaian gaya Bahasa bertujuan untuk menyampaikan maksud atau sesuatu dengan Bahasa yang lebih halus atau memiliki ciri khas tersendiri.

Tarigan (1986: 163) kemudian membagi jenisjenis gaya Bahasa ke dalam empat bagian, yaitu: (1) gaya Bahasa perbandingan (perumpamaan, metafora, personifikasi, alegori, antithesis, pleonasme, periphrasis, antisipasi, koreksio), (2) gaya bahasa pertentangan (hiperbola, litotes, ironi, oksimoron, paronomasia, paralipsis, zeugma, innuendo, antifrasis, paradok, klimak, antiklimak, apostrof, anastrof, apofasis, proteron, hipalase, sinisme, sarkasme), (3) gaya Bahasa pertautan (metonimia, sinekdok, alusi, eufimisme, eponym, epitet, antonomasia, erotesis, paralelisme, ellipsis, asyndeton, polisindeton), (4) gaya Bahasa perulangan (alitrasi, asonami, kiasmus, apizeukis, taupotes, anaphora, epistrofa, simploke, mesodiplosis, anadiplosis).

Gaya Bahasa khas Bali menurut I Wayan Simpen (1982: 5) disebut dengan istilah basita paribasa. Basita paribasa merupakan Bahasa yang mengandung arti kiasan dan menyimpang dari arti sebenarnya, karena dalam satu ungkapan bisa mengandung dua arti atau lebih. I Wayan Simpen membagi basita paribasa yang dipakai dalam percakapan atau pergaulan umum pada masyarakat Bali, menjadi 16 jenis, yaitu: (1) sesonggan (pepatah), (2) sesenggakan (ibarat), (3) wewangsalan (tamsil),
(4) sloka (bidal), (5) bebladbadan (metafora), (6) paparikan (pantun), (7) papindan (perumpamaan), (8) sasawangan (perumpamaan), (9) cecimpedan (teka-teki), (10) cecangkriman (syair teka-teki), (11) cecangkitan (olok-olokan), (12) raos ngempelin (kata yang memiliki dua arti), (13) sesimbing (sindiran), (14) sasemon (sindiran halus), (15) sipta, dan (16) sesapaan (doa). Gaya Bahasa yang terdapat dalam Geguritan Suddhamala akan dipaparkan sebagai berikut :

\section{a. Gaya BahasaLitotes}

Gaya Bahasa litotes merupakan gaya Bahasa yang mengandung pernyataan dikecil-kecilkan, dikurangi dari kenyataan yang sebenarnya, misalnya untuk merendahkan diri (Tarigan, 1985: 58). Gaya Bahasa ini digunakan untuk merendahkan diri atau sesuatu yang disampaikan mengurangi keadaan sebenarnya (Keraf, 2004: 133). Gaya Bahasa litotes dalam Geguritan Suddhamala digunakan oleh pengarang naskah untuk merendahkan dirinya, pengarang menganggap dirinya masih bodoh tetapi mencoba untuk membuat suatu naskah karya sastra. Berikut kutipannya:

...//Iseng titiang muruk nyurat/ tatwa suddhamala kambil/ anggen muruk ngawi tembang/ nanging twara manut indik/ pupuh basa kirang rawit/ madasar manahe kudhu/ anggen ngalimbakang satwa/ tan lali nunas aksami/ ring $i$ ratu/ miwah ida dane samyan// (Pupuh Sinom Bait 1)

Terjemahannya :

...//Iseng saya belajar menulis/ mengambil kisah Suddhamala/ saya pakai belajar membuat tembang/tetapi tidak sesuai dengan sastra yang indah/ pupuh dan bahasanya kurang jelas/ didasari kemampuan yang kurang/ pakai untuk menceritakan cerita/tidak lupa mohon maaf/ kemada yang mulia/ dan juga anda semuanya//

Berdasarkan kutipan pupuh sinom di atas pengarang menganggap karyanya ini tidak ada bagus karena beliau baru belajar serta karyanya tidak sesuai dengan kaidah penulisan sastra. Pengarang membuat karya sastra ini bertujuan untuk menceritakan kembali siapakah sebenarnya orang yang mampu membebaskan segala dosa dan hukuman. Pengarang merasa dirinya tidak pantas menulis, hasil karyanya tidak ada artinya padahal setelah dihayati karyanya mengandung nilai pendidikan yang diperlukan untuk menumbuhkan karakter budi pekerti luhur.

Selanjutnya hal yang sama juga terjadi didalam cerita dimana saat Dewi Uma bercakap-cakap dengan Dewa Siwa, berikut kutipanya.

.../Bhatara Siwa angucap/ wacanane sada aris/ Mawosang sungkane rahat/ bhatari sarwi nyaurin/ Naweg titiang nene mangkin/ antuk nambete kalintang/ napi anggen titiang tamba/ tan kamanahan antuk mangkin/ inggih ratu/ durusang titiang nikayang// (Pupuh Sinom bait 4) 
Terjemahannya :

...//Dewa siwa berkata/ perkataanya sangat pelan/ mengatakan sakitnya sangat berat/ kemudian dijawab oleh Dewi Uma/saya sekarang memohon ijin/ karena saya sangat bodoh/ apa yang saya pakai obat/ tidak terpikirkan oleh saya/ baiklah kanda/ sampaikanlah kepada saya//

Berdasarkan kutipan pupuh sinom di atas, pada kalimat "antuk tambete kalintang" yang artinya "karena sangat bodoh" Dewi Uma yang merupakan sosok Dewi atau Saktinya Dewa Siwa menganggap dirinya sangatlah bodoh, padahal sebenarnya bukan bodoh.

\section{b. Gaya Bahasa Perumpamaan}

Gaya Bahasa perumpamaan merupakan gaya Bahasa yang menggunakan perbandingan dua hal yang pada hakikatnya berlainan, dengan sengaja dianggap sama (Tarigan, 1985: 9). Menurut Keraf (2004: 138) menyebutkan gaya Bahasa perumpamaan gaya Bahasa persamaan, yaitu gaya Bahasa perbandingan yang bersifat eksplisit, atau gaya Bahasa yang langsung menyatakan sesuatu sama dengan hal lain. Gaya Bahasa perumpamaan dalam Geguritan Suddhamala digunakan untuk memperindah suatu karya sastra geguritan itu sendiri. Terdapat dalam kutipan berikut ini.

...//Suenya apanalikan/ saling pandreng sareng kalih/ bhatari nuli asredah/ antukan eling ring janjil nenten keturin mawali/ sadurunge polih susu/ raris mawacana banban/Pinunasnya kadagingin/ sampun puput/ raris katurin empehan// (Pupuh Sinom bait 15)

Terjemahannya :

...//Sangatlah lama/ saling lihat berduaan/ dewi uma lalu terperengah/karena ingat dengan janji/ tidak diijinkan kembali/ sebelum mendapatkan susu/ lalu berbicara pelan/ keinginannya terpenuhi/ setelah selesai/ lalu diberikan susu/

Berdasarkan kutipan di atas, dipaparkan pengarang menggunakan istilah "Suenya apanalikan" merupakan perumpamaan untuk menggambarkan waktu yang sangat lama, dimana "apanalikan" itu memiliki arti sampai pergantian tahun "apanalikan warsa". Penggunaan istilah ini menambah keindahan dari karya sastra serta penggunaan bahasanya terasa mimiliki rasa yang halus. Istilah yang digunakan akan mempermudah para pembaca untuk menghayati isi dari karya sastra geguritan ini.

\section{c. Gaya BahasaAntitesis}

Menurut Tarigan (1985: 27) gaya Bahasa Antitesis merupakan gaya Bahasa yang mengadakan komparasi atau perbandingan antara dua antonim, yaitu gaya Bahasa yang menggunakan kata-kata yang mengandung ciri-ciri semantik yang saling bertentangan. Gaya Bahasa Antitesis dalam
Geguritan Suddhamala digunakan untuk membandingkan suatu kata yang berfungsi untuk memberikan pengertian lawan kata sehingga lebih mudah untuk memahami isi dari karya sastra tersebut. Gaya Bahasa antithesis yang dimaksud terdapat dalam kutipan berikut ini :

...//Uduh watek kala-kali/...//

(Pupuh Ginada bait 26, Baris ke-2)

Terjemahannyanya :

"Wahai para kala (laki-laki) kali (perempuan)"

Berdasarkan kutipan di atas seluruhnya menggunakan gaya Bahasa antitesis yang membandingkan kata yang satu dengan lainnya yang bermakna jenis kelamin. Dengan adanya gaya Bahasa ini pembaca akan lebih mudah memahami maksud serta tujuan sang pengarang.

d. Gaya Bahasapleonasme

Trigan (1985: 29) berpendapat gaya Bahasa pleonasme merupakan pemakaian kata yang mubazir yang jika dihilangkan artinya tetap. Keraf (2004: 133) mengemukakan gaya Bahasa pleonasme merupakan gaya Bahasa yang mempergunakan kata-kata yang lebih daripada diperlukan untuk menyatakan satu pikiran atau gagasan. Gaya Bahasa pleonasme digunakan untuk mengeraskan arti dari kata yang diucapkan. Geguritan Suddhamala dapat ditemukan ada beberapa kata yang mengandung gaya Bahasa pleonasme, seperti dalam kutipan berikut ini:

...//Tan ucapan maring jalan/ ring setra rauh mangkin/ kasambra maring Hyang Durga/ Bagya cening mai rauh/ apa krana cening palas/ ring widyadari/ sang kalih matur nguningang// (Pupuh Ginada bait 4)

Terjemahannya :

...//Tidak diceritakan dalam perjalanan/ tibalah dikuburan/ disambut oleh dewi Durga/ bahagya ananda datang kesini/ apa yang menyebabkan ananda berpisah/ dengan bidadari/ keduanya lalu menyampaikan//

Kutipan kalimat "Bagya cening mai rauh" di atas jelas menjelaskan bahwa kalimat tersebut apabila salah satu katanya dihilangkan artinya masih sama. Gaya Bahasa pleonasme tersebut digunakan untuk lebih memberikan pemahaman secara mendalam untuk menghayati karya sastra. Kata tersebut digunakan berfungsi juga untuk mengikuti aturann dari pembuatan pupuh ginada tersebut.

\section{e. Gaya Bahasa Hiperbola}

Tarigan (1985: 55) menyatakan hiperbola adalah gaya Bahasa yang mengandung pernyataan melebihlebihkan dari segi jumlah, ukuran atau sifat, dengan maksud memberikan penekanan pada suatu pernyataan atau situasi, guna memperhebat/ meningkatkan kesan dan pengaruhnya. Gaya Bahasa hiperbola merupakan gaya Bahasa yang mengandung suatu pernyataan berlebihan, dengan membesar-besarkan sesuatu hal. Gaya Bahasa hiperbola digunakan dalam membangun teks Geguritan Suddhamala, seperti terdapat dalam kutipan berikut ini : 
Terjemahannyanya:

..//sakit tenggorokan sampai terbalik/..//

...//Reh cening dhanuja luwih/...//

(Pupuh Ginada Bait ke-10, Baris ke-2)

Terjemahannyanya:

..//Karena ananda kesatria yang terbaik/...//

...//ane pecak ayu luih/..//

Terjemahannyanya:

(Pupuh Sinom bait 19 baris 5

..//yang biasanya cantik terbaik/...//

Berdasarkan kutipan di atas mempergunakan gaya Bahasa hiperbola untuk memberikan pemahaman yang sangat mendalam kepada para pembaca. Penggunaan gaya Bahasa hiperbola yang bahwasannya melebihlebihkan suatu sifat bertujuan untuk memberikan penekanan pada kalimat tersebut. Dengan begitu pembaca akan memfokuskan pembacaannya kepada kalimat tersebut dan mudah untuk menghayati makna yang terkandung dalam karaya sastra ini.

\section{f. Gaya BahasaAntonomasia}

Antonomasia adalah gaya Bahasa penggunaan gelar resmi atau jabatan sebagai pengganti nama diri (Tarigan, 1985: 132). Gaya Bahasa antonomasia yang terdapat dalam Geguritan Suddhamala disebutkan istilah penyebutan Tuhan, orang ahli dalam sastra dan Pendeta ada berbagai jenis. Penyebutan tersebut bertujuan untuk menambah kasanah dalam berbahasa. Walaupun demikian tidak mengurangi makna dari isi karya sastra ini. Penggunaan gaya Bahasa antonomasia dalam Geguritan Suddhamala adalah sebagai berikut:

...//Ida Sang Hyang Giri Putri/..//

Terjemahannya:

(Pupuh Sinom Bait ke2, baris ke-2)

...//Beliau Dewi Uma/...//

...//olih Sang Pandhuputra ngruat/ putran ida pinih alit/..//

(Pupuh Durma Sinom bait 19, baris ke 3;4)

Terjemahannya:

...//oleh anaknya sang Pandu menyucikan/ anaknya yang paling kecil/...//

...//Hyang Guru Ida nyupat//

Terjemahannya:

(Pupuh Ginada bait 1, baris 7)

...//Dewa Siwa beliau mengutuk//

Nama-nama julukan seperti Hyang Giri Putri untuk mengganti nama Dewi Uma, Sang Pandu Putra pinih alit untuk mengganti nama Sahadewa serta Hyang Guru untuk mengganti nama Dewa Siwa merupakan namanama lain untuk menggantikan nama aslinya sehingga dalam membuat pupuh sesuai dengan pada lingsa dan guru wilang. 


\section{SIMPULAN}

Struktur forma meliputi: kode bahasa dan sastra, ragam bahasa dan gaya bahasa yang digunakan dalam membangun karya sastra. Kode bahasa sastra yang ada dalam Geguritan Suddhamala ini yakni menggunakan 182 bait (pada) pupuh dan terdiri atas 22 bait Pupuh Sinom, 46 bait Pupuh Ginada, 51 bait Pupuh Durma, 18 bait Pupuh Semarandana, 30 bait Pupuh Pangkur dan 15 bait Pupuh Dangdang Gula. Ragam bahasa yang digunakan dalam Geguritan Suddhamala ini menggunakan Bahasa Bali Alus, Bahasa Bali Madya, dan Bahasa Bali Kasar. Gaya bahasa yang digunakan dalam Geguritan Suddhamala menggunakan majas litotes, majas perumpamaan, majas antitesis, majas pleonasme, majas hiperbola dan majas antonomasia.

\section{DAFTAR PUSTAKA}

Esten,Mursal. 1984. Kesusastraan Pengantar Teori dan Sejarah. Bandung: Angkasa.

Gautama, Wayan Budha. 2007. Kesusastraan Bali. Surabaya: Paramita.

Granoka, Ida Wayan Oka, dkk. 1996. Tata Bahasa Baku Bahasa Bali. Denpasar: Pemerintah Propinsi Daerah Tingkat I Bali.

Narayani, Eka. 2007. Geguritan Watugunung Analisis Struktur dan Semiotik. Skripsi (tidak diterbitkan). Jurusan Sastra Daerah, Universitas Udayana Denpasar.

Riken, Made dkk. 1996. Materi Pokok Bahasa Daerah Bali. Jakarta: Derektorat Jenderal Bimbingan Masyarakat Hindu dan Buddha.

Sudarsana, I. K. (2017). Interpretation Meaning of Ngaben for Krama Dadia Arya Kubontubuh Tirtha Sari Ulakan Village Karangasem District (Hindu Religious Education Perspective). Vidyottama Sanatana: International Journal of Hindu Science and Religious Studies, 1(1), 1-13.

Suharianto, S. 1982. Dasar-dasar Teori Sastra. Jakarta: Widya Duta

Sukada, I Made. 1987. Beberapa Aspek tentang Sastra. Denpasar: Kayumas dan Yayasan Seni Lisibha.

Sumaryono, E. 1999. Hermeneutika Sebuah Metode Filsafat. Yogyakarta: Kanisius.

Tarigan, Henry Guntur. 1984. Prinsip-prinsip Dasar Sastra. Bandung : Angkasa.

Teeuw, A. 1991. Membaca dan Menelaah Sastra. Jakarta: Gramedia.

Widiana, I Ketut. 2010. Analisis Amanat Geguritan Prabhu Karna Lampus. Skripsi (tidak diterbitkan). Denpasar: IHDN Denpasar. 